\title{
Duration of decubitus position after epidural blood patch
}

Thirty patients presenting with post-dural puncture headache (PDPH) were prospectively studied to determine the influence of the duration of the decubitus position afier epidural blood patch on the efficacy of treatment. All patients received $12 \mathrm{ml}$ of autologous blood. They were randomly distributed into three groups of ten patients. Patients in Group 1 were maintained in a decubitus position for $30 \mathrm{~min}$ after the epidural injection of autologous blood in the epidural space. Patients in Group 2 were maintained for $60 \mathrm{~min}$ in decubitus and patients in Group 3 for $120 \mathrm{~min}$. Post-dural puncture headache was evaluated using a visual analogue scale before the epidural blood patch, at the time of initially adopting a standing position after the blood patch, and $24 \mathrm{hr}$ later. The severity of PDPH in the three groups was reduced at the time of initially adopting a standing position and after $24 \mathrm{hr}$, in comparison with preblood patch VAS $(P<0.001)$. Patients in Group 3 presented less severe PDPH than patients in Group 1 at the time of initially standing up and $24 \mathrm{hr}$ later $(P<0.05)$. We conclude that epidural blood patch was effective in treating PDPH but that the maintenance of a decubitus position for at least one hour and preferably for two hours after the blood patch was more effective than maintenance for $30 \mathrm{~min}$.

Trente patients qui présentaient des céphalées après une perforation de la dure-mère ont été étudiés de façon prospective. Linfluence de la durée du decubitus après linjection de sang autologue dans l'espace épidural sur l'efficacité du traitement a été évaluée. Tous les patients ont reçu $12 \mathrm{ml}$ de sang autologue dans l'espace epidural. Ils ont été répartis au hasard en trois groupes de dix patients chacun. Les patients du groupe 1 ont

\section{Key words}

ANAESTHETIC TECHNIQUES: spinal;

COMPLICATIONS: headache.

From the department of Anaesthesia, University of

Sherbrooke, Sherbrooke, Quebec.

Presented in part at the annual meeting of the Canadian

Anaesthetist's Society, Halifax, 1993.

Address correspondence to: Dr. René Martin, Department

of Anaesthesia, C.H.U. Sherbrooke, 3001, 12th Avenue North,

Fleurimont, Quebec, J1N 5N4.

Accepted for publication Ist October, 1993. maintenu une position décubitus pendant 30 min après le traitement. Les patients du groupe 2 ont maintenu cette position pendant $60 \mathrm{~min}$ et ceux du groupe 3, $120 \mathrm{~min}$. Lintensité de la céphalée était évaluée au moyen d'une échelle visuelle analogue avant le traitement, au moment du lever, et 24 heures après le traitement. Les patients des trois groupes ont vu leurs céphalées diminuer de façon significative au moment du lever ainsi que 24 heures après linjection de sang autologue dans l'espace épidural $(P<0.001)$. Les patients du groupe 3 présentaient cependant des céphalées moins importantes que les patients du groupe 1 au lever $(P<0.05)$ et 24 heures plus tard $(P<0.05)$. Nous concluons que le maintien diune position de décubitus pendant au moins une heure et préférablement deux heures après linjection de sang autologue dans l'espace épidural donne de meilleurs résultats que le maintien de cette position pendant seulement 30 minutes.

Epidural blood patch is a recognized treatment for postdural puncture headache (PDPH). ${ }^{1}$ Its success may be related to closure of the hole in the dura by injection of autologous blood into the epidural space. Good results are expected in 90 to $95 \%$ of the cases, ${ }^{1}$ but there is still a 5 to $10 \%$ failure rate which may be related to a faulty technique, to a patch performed too early, ${ }^{2}$ or to other unknown factors. We considered that as the cerebrospinal fluid production rate is 0.3 to $0.35 \mathrm{ml} \cdot \mathrm{min}^{-1}$, and the withdrawal of $20 \mathrm{ml}$ of spinal fluid results in headache, which is relieved by reinjection, ${ }^{4}$ the duration of the decubitus position after performing the blood patch may influence the efficacy of treatment, allowing more or less time for CSF to regenerate. The present prospective study was thus conducted to evaluate this aspect of epidural blood patch.

\section{Methods}

Following ethics approval and written informed consent, 30 consecutive patients referred to the department of anaesthesia for PDPH were studied. They were divided, according to a random number table, into three groups of ten patients. Patients in Group 1 were instructed to maintain a dorsal decubitus position for $30 \mathrm{~min}$ after their blood patch before adopting a standing position. Patients in Group 2 maintained a decubitus position for $60 \mathrm{~min}$ 
TABLE I Demographic data*

\begin{tabular}{llll}
\hline & Group 1 & Group 2 & Group 3 \\
\hline$n$ & 10 & 10 & 10 \\
Sex (F/M) & $8 / 2$ & $8 / 2$ & $6 / 4$ \\
Age (yr \pm SD) & $39.5 \pm 15$ & $38.7 \pm 7$ & $38.3 \pm 12$ \\
Aetiology of PDPH & Diagnostic LP =5 & Diagnostic LP =6 & Diagnostic LP =6 \\
& Epidural anaesth. $=1$ & Myelography $=4$ & Spinal anaesth. =1 \\
& Spinal anaesth. $=1$ & & Myelography = 3 \\
Duration of PDPH (days) $n+$ SD & $4.4 \pm 2.9$ & $6.5 \pm 6$ & $7.1 \pm 6.1$ \\
\hline
\end{tabular}

$* P=\mathrm{NS}$

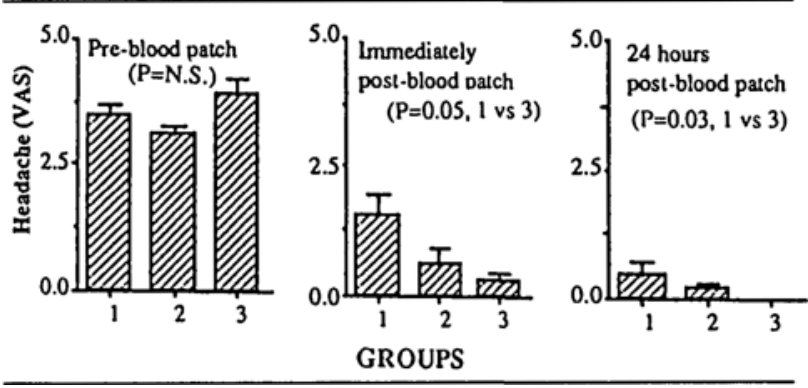

FIGURE Severity of post-dural puncture headache before, after and $24 \mathrm{hr}$ post-epidural blood patch in the three groups of patient studied as evaluated by a visual analogue scale (VAS) (Mann-Whitney $\mathrm{U}$ tests).

and patients in Group 3 maintained the decubitus position for $120 \mathrm{~min}$ before standing up. Autologous blood, $12 \mathrm{ml}$, was injected into the lumbar epidural space of all patients, at the site of or one space above or below the site of the dural puncture. The technique was standardized for all patients and was performed in the lateral decubitus position, using sterile precautions. The blood was injected at the rate of $1 \mathrm{ml}$ per $2 \mathrm{sec}$ approximately. If the patient complained of pain in the back or in the legs at the time of the injection, the rate of injection was reduced. No technical difficulties were encountered in any patient. The PDPH intensity was evaluated with a visual analog scale (VAS) before the blood patch, at the time of standing up after the blood patch and $24 \mathrm{hr}$ later. The scale used varied from 0 to $5 ; 0$ being no headache and 5 the worst headache that could be imagined.

Demographic data were also noted, including the duration of headache and the nature of the technique responsible for the PDPH.

Statistical analysis consisted of an analysis of variance (ANOVA) for parametric results (age, duration of headache), a chi-square test for sex, Friedman and Wilcoxon tests for VAS scores before and after blood patch in each group, and Kruskal-Wallis and Mann-Whitney $U$ tests for VAS comparisons between groups. A $P \leq 0.05$ was considered statistically significant.

\section{Results}

There were no differences between the three groups concerning sex, age, aetiology of PDPH and duration of headache before the epidural blood patch (Table I).

The intensity of the PDPH was evaluated as about $3 / 5$ in the three groups before the blood patch (Figure). When compared with the pre-blood patch headache intensity, all the patients in the three groups noted an improvement of their headache at the time of adopting the standing position and $24 \mathrm{hr}$ later (Figure) $(P<0.001)$, Friedman test for multiple within groups comparisons. However, at the time of adopting the standing position initially and $24 \mathrm{hr}$ later (Figure), patients in Group 1 presented more severe headache than patients in Group $3(P=0.05)$, Mann-Whitney test for between groups comparisons, with four patients still presenting with some headache $24 \mathrm{hr}$ after blood patch in Group 1 compared with none in Group 3 (Table II).

\section{Discussion}

The present study shows that the duration of maintaining the decubitus position after epidural blood patch could be a factor in the incomplete relief of PDPH. Twentyfour hours after the blood patch, no patient in the group of patients who were kept in a decubitus position for two hours after the blood patch had headache, but two in Group 2 (duration of decubitus = one hour) and four in Group 1 (duration of decubitus $=30 \mathrm{~min}$ ) still presented with headache (Table II). The present study also confirms the efficacy of epidural blood patch in controlling PDPH.

The reason for the influence of the duration decubitus position after epidural blood patch could be related to the rate of CSF production, which is 0.3 to 0.35 $\mathrm{ml} \cdot \mathrm{min}^{-1} \cdot{ }^{3}$ It is known that a $20 \mathrm{ml}$ loss of CSF results in headache which is relieved by reinjection. ${ }^{4}$ Thus, if we presume that at least $20 \mathrm{ml}$ of CSF is missing, one hour or more is necessary for its regeneration. This would explain the better results in the two-hour group and the reason why some patients still presented with some head- 
TABLE II Number of patients still presenting headache after epidural blood patch

\begin{tabular}{llll}
\hline & Group 1 & Group 2 & Group 3 \\
\hline At initial standing up & $7 / 10$ & $4 / 10$ & $3 / 10$ \\
$24 \mathrm{hr}$ later & $4 / 10$ & $2 / 10$ & $0 / 10$ \\
\hline
\end{tabular}

ache when adopting a standing position $30 \mathrm{~min}$ or one hour after the blood patch no longer had headache 24 hr later (Table II). The fact that four patients still complained of headache $24 \mathrm{hr}$ after epidural blood patch in Group 1 might be related to the quality of the clot. There is rapid coagulation when blood is mixed with cerebrospinal fluid in dogs, ${ }^{5}$ which could be related to the procoagulant activity of the CSF. ${ }^{6}$ In fact, in the absence of CSF, the coagulation process is four times slower and the clot formed is less solid than when CSF mixed with blood. ${ }^{5}$ Our patients had their headaches for about five to seven days (Table I). Consequently, we presume that they had tried to stand up many times during that time and that CSF had leaked into their epidural spaces. Could a clot formed with the mixture of CSF and blood be more haemostatic after two hours than after $30 \mathrm{~min}$ ? We measured, in two subjects not included in the study, the retraction of the clot after mixing CSF and blood. On a scale varying from 0 to +5 , the clot retraction was +1 after 30 min and +3 after two hours in both subjects, but we do not know if a more retracted clot in vitro provides a better haemostatic plug in vivo.

The present study was not double-blind. The patients signed an informed consent where it was stated that we were studying the duration of decubitus after epidural blood patch. They were told at the time that we were unable to predict the results of the study and that they would obtain an efficacious treatment for their PDPH in whatever the group they were allocated.

The results of this study are probably more in favour of clotted blood covering the dural hole and preventing leakage of CSF than of a mechanism involving increased epidural and subarachnoid pressure secondary to the injection of blood, but this cannot be excluded. ${ }^{7}$ The volume of $12 \mathrm{ml}$ which was used in this study was based on a study using a radioisotope imaging technique which concluded that $14.8 \mathrm{ml}$ of blood injected into the epidural space spread an average of nine spinal segments. We concluded that $12-15 \mathrm{ml}$ was the ideal amount of blood required to relieve PDPH. ${ }^{8}$

In conclusion, the results of this study suggest that the duration of the decubitus position after epidural blood patch influences the efficacy of the technique in treating PDPH in the first $24 \mathrm{hr}$ following the blood patch. We suggest at least a one hour but preferably a two hour duration of decubitus position after an epidural blood patch. No patient kept in a decubitus position for two hours complained of headache $24 \mathrm{hr}$ later, whereas four and two patients out of 10 still had some headache when the decubitus time was reduced to $30 \mathrm{~min}$ and one hour respectively.

\section{References}

1 Gielen M. Post dural puncture headache (PDPH): a review. Reg Anesth 1989; 14: 101-6.

2 Loeser EA, Hill GE, Bennet GM, Sederberg JH. Time vs success rate for epidural blood patch. Anesthesiology 1978; 49: 147-8.

3 Shapiro HM. Neurosurgical anesthesia and intracranial hypertension. In: Miller RD (Ed.). Anesthesia, 2nd ed., New York: Churchill Livingstone Inc., 1986: 1564.

4 Kunkle EC, Ray BS, Wolff HG. Experimental studies on headache: analysis of the headache associated with changes in intracranial pressure. Arch Neurol 1943; 49: 323-58.

5 Cook MA, Watkins-Pitchford JM. Epidural blood patch: a rapid coagulation response (Letter). Anesth Analg 1990; 70: 567.

6 Nagda KK. Procoagulant activity of cerebrospinal fluid in health and disease. Indian J Med Res 1981; 74: 107-10.

7 Carrie LES. Epidural blood patch: why the rapid response? (Letter). Anesth Analg 1991; 72: 129-30.

8 Szeinfeld M, Ihmeidan IH, Moser MM, Machado R, Klose KJ, Serafini $A N$. Epidural blood patch: evaluation of the volume and spread of blood injected into the epidural space. Anesthesiology 1986; 64: 820-2. 